\title{
A Study on the Relationship between Monetary Policy Variables and Stock Market
}

\author{
Song $\mathrm{Li}^{1}$ \\ ${ }^{1}$ School of Economics, Ocean University of China, Qingdao, China \\ Correspondence: Song Li, School of Economics, Ocean University of China, NO.238, SongLing Road, LaoShan \\ District, Qingdao, China. E-mail: 15764212953@163.com
}

Received: November 14, 2017

Accepted: November 28, 2017

Online Published: December 20, 2017

doi:10.5539/ijbm.v13n1p218

URL: https://doi.org/10.5539/ijbm.v13n1p218

\begin{abstract}
Through the analysis of monetary policy variables and stock market from January 2010 to December 2015, including money supply M1, M2,one-year Benchmark lending rate for financial institutions, interbank offered rate, and the stock market price index data, through correlation analysis, unit root test, co-integration test, Granger causality test and VAR model test, empirical test results show that there is a two-way causal relationship between money supply M1 and stock market, M2 and stock market have a one-way causal relationship from M2 to stock market. One-year benchmark lending rate for financial institutions and stock market have a one-way causal relationship from stock market to one-year benchmark lending rate for financial institutions. The interbank offered rate and the stock market have a one-way causal relationship from the stock market to the interbank offered rate. China's transmission channels between monetary policy and stock market exist, but is not sound and there is a delay. When using the monetary policy variable to adjust the stock market, the money supply policy is more useful than adjusting the interest rate.
\end{abstract}

Keywords: Co-integration Test, Granger Causality Test, Monetary Policy variables, Model of VAR, Stock Market

\section{Introduction}

\subsection{Research Background}

Since July 2014, China's new bull market has begun to emerge.。 In December 2014, the financial stocks which are represented by brokerage, banking, insurance stocks suddenly burst, led the Chinese stock market in experiencing a new round of bull market. Shanghai Composite Index soared and once reached the peak point of 5178.19. Then turned down into the long-term adjustment interval. Some people believe that the root cause of the round of bull market are policy guidance, the decline of risk-free income, the stock market has been down for a long time and technical aspects.

We can't ignore that China's monetary policy variables adjusted repeatedly and consequently had different effects on the market during the round of bull market. For example, the benchmark interest rate of RMB deposit and loan for financial institutions has been come down 5 times from November 22th, 2014 to October 24th, 2015.

So what's the specific effects of the adjustments of China's monetary policy variables on the stock market? Whether China's stock market monetary policy transmission mechanism is mature? Here we use empirical methods to analyse the two-way correlation between the stock market and China's monetary policy variables.

\subsection{Related Theories}

1.2.1 The Mechanism of Monetary PolicyVariables on the Stock Market:

(1) The effect of money supply on stock prices: This effect can be achieved through three effects: expected effect, portfolio effect and intrinsic value growth of stock effect. The central bank will make stock prices rise when implementing more loose monetary policies.

(2) The effect of interest rates on stock prices: When interest rate falls, the impact is achieved mainly through three roles: firstly, the opportunity cost to invest in the stock market is reduced, leading more capital investing in the market and consequently rising stock prices. Secondly, financing cost of corporate declines, leading to 
increasing investment and expanding production, thus increasing profits and causing stock prices rise. Thirdly, the investor's required return is reduced, and then the discount rate in the stock pricing model declines and the stock price rises. To sum up, more loose monetary policy will lead to rising stock prices, bringing the stock market boom.

\subsubsection{The Mechanism of the Stock Market on Monetary Policy Variables:}

(1) The effect of stock prices on money supply: M. Friedman's classic study points out that stock prices affect the money supply by four ways: wealth effect, portfolio effect, trading effect and substitution effect. In the first three effects, a positive stock market will result in an increase in the demand for money. The latter effect reduces the demand for money through stock substitution of the currency.

(2) The effect of stock prices on interest rates: From Tobin's q theory, it is concluded that the rise of the stock price will lead to the increase of the company's investment and the rise of the interest rate. However, interest rates are determined by the supply and the demand of funds. Therefore, the stock market's effect on interest rates can't be considered solely on the basis of changes in stock prices. At the same time, China's marketization of interest rate has not yet been fully realized, and the impact of stock prices on the interest rate is also determined by monetary authorities' judgment on macro-economic conditions.

\section{Literature Review}

Over the years, scholars in China have done a great deal of research on the relationship between the monetary policy and the stock market. Qian Xiaoan (1998) used the static regression and variance decomposition methods to test the correlation between the money supply and the stock price from March 1994 to February 1997. The results show that the stock price changes in the same direction with $\mathrm{M} 0$, has nothing to do with $\mathrm{M} 1$, and reverses with M2. Their correlation are weak and unstable. Yang Xinsong and Long Gesheng (2006) used co-integration test, Granger causality test and vector autoregressive model to analyze the correlation between the money supply and the stock market. They concluded that there is a two-way causal relationship between M1, M2 and market capitalization. Nominal interest rate, the real interest rate is the Granger reason of stock market capitalization. The central bank can adjust the stock market through the money supply and interest rate, and the interest rate is more effective. According to HP filter, Granger causality test, prediction variance decomposition and time-varying parametric state-space model, Xue Yonggang and Chao Yanming (2008) studied the relationship between the loan rates of commercial banks, M1, M2, interbank offered rate and the stock price from January 1998 to February 2007. The results show that there is an incomplete two-way causal relationship between China's monetary policy variables and stock prices. The stock market transmission channels exist but is not very efficient. The counter-effect of stock price on monetary policy variables is stronger than the positive effect. Cui Xiuhong and Xie Xuecheng (2012) studied the price-type variables, quantitative variables and credit conditions in China from January 1999 to October 2009 through VAR model. The results show that the return of stock market is insensitive to the official interest rate adjustment of deposit and lending rates, while it is sensitive to the quantitative response of bank loans and M2. At the same time, the response of the stock market of our country to the adjustment of monetary policy has obvious state-dependent characteristics. Zhang Xiuli (2012) analyzed the data of money supply and stock market prices from January 2001 to December 2011 by using empirical research methods such as unit root test, co-integration test and Granger causality test. The results show that the impact of different levels of money supply on the stock market is not the same. There is a long-term equilibrium relationship between M1 and the stock market price, and M0 and M2 have no significant effect on the stock market.

Due to the different degrees of maturity of China's stock market in different periods, their research results are different. Under the background of the marketization reform of interest rate in China and the bull stock market in 2015, this paper draws on the previous research methods and adopts correlation test, unit root test, co-integration test, Granger causality test and VAR model to analyze the two-way dynamic linkages between the Shanghai Composite Index and the money supply (M1, M2) and interest rates (interbank offered rate R2, the benchmark interest rate of financial institution's one-year loan R1) from January 2010 to December 2015. Based on this, we can prove the effectiveness of monetary policy to intervene in the stock market and the maturity of China's transmission channel between the money market and the stock market, and then put forward policy recommendations.

\section{Empirical Analysis}

\subsection{The Selection of Sample Data}

In the empirical analysis, this paper uses a total of 72 sets of data from January 2010 to December 2015. Using 
the monthly highest point of the Shanghai Composite Index (SP) to represent the status of China's stock market. Using M1, M2, the two money supply level as Money supply (100 million yuan). The interest rate is based on the interbank offered rate R2 (7 days) and the financial institution's one-year loan benchmark interest rate R1 (\%).The above data are from the People's Bank of China Survey and Statistics Division.

Before the specific analysis, we do data pre-processing firstly, that is, to make seasonal adjustment and take the natural logarithm to the above variables (except for interest rate variables).

\subsection{Correlation Test}

Before establishing autoregressive model, this paper do correlation test firstly to see whether there is a certain correlation. Test results in Table 1.

Table 1. the Results of correlation test

\begin{tabular}{llllll}
\hline Correlation coefficient & M1 & M2 & R1 & R2 & SP \\
\hline M1 & 1.000000 & 0.988114 & -0.25316 & 0.263673 & -0.01786 \\
M2 & 0.988114 & 1.000000 & -0.23409 & 0.254538 & -0.04556 \\
R1 & -0.25316 & -0.23409 & 1.000000 & 0.594050 & -0.60767 \\
R2 & 0.263673 & 0.254538 & 0.594050 & 1.000000 & -0.40805 \\
SP & -0.01786 & -0.04556 & -0.60767 & -0.40805 & 1.000000 \\
\hline
\end{tabular}

The results show that the money supply M1, M2, financial institution's one-year benchmark lending rate, interbank offered interest rates, the Shanghai Composite Index, there is a linear relationship between the two.

\subsection{Unit Root Test}

Then this paper carry out unit root test for each variable to test whether the data is stable and has a trend of time, so as to avoid the false regression phenomenon in the following regression analysis. In practice, the time series are often not stable. In this paper, we use ADF statistics, using eviews7.2 measurement software to do unit root test for M1, M2, R1, R2, SP respectively. Test results are in Table II.

Table 2. Test results of unit root test

\begin{tabular}{lllll}
\hline The results of ADF & T-statistics & Prob. & 5\% Critical Level & Time Lag \\
\hline M1 & -0.3755 & 0.9069 & Contains unit root, non-stationary & 1 \\
D (M1) & -10.56846 & 0.0001 & Excluding unit root, stable & 0 \\
M2 & -1.813005 & 0.3714 & Contains unit root, non-stationary & 0 \\
D (M2) & -9.880969 & 0 & Excluding unit root, stable & 0 \\
R1 & -0.287945 & 0.9206 & Contains unit root, non-stationary & 2 \\
D (R1) & -3.35132 & 0.0163 & Excluding unit root, stable & 1 \\
R2 & -3.37878 & 0.015 & Excluding unit root, stable & 0 \\
D (R2) & -8.221654 & 0 & Excluding unit root, stable & 1 \\
SP & -1.719646 & 0.4171 & Contains unit root, non-stationary & 1 \\
D (SP) & -6.025473 & 0 & Excluding unit root, stable & 0
\end{tabular}

Note: $\mathrm{D}()$ is first order difference. The lag period is determined according to SIC guidelines. The T-test had a critical value of -3.527045 at $1 \%$ significance level and -2.903566 at the 5\% significance level, and -2.985227 at the $10 \%$ significance level.

The results in Table 4 show that M1, M2, R1, SP are not stable time series and have a time trend, but R2 is a stationary series. However, the first-order differences of M1, M2, R1, R2 and SP are all stable, so we can think that all of these five variables as first order sequence I (1).

\subsection{Co-integration Test}

Since the money supply M1, M2, R1, R2, SP are first-order single integer sequences, if they have the co-integration relationship, then the regression model can be established. Therefore, we do co-integration test for the five variables. In this paper, Johansen test is used, and the lag number is 2 based on AIC and SC criteria. Test results are shown in Table III. 
Table 3. the results of co-integration test

\begin{tabular}{lllll}
\hline $\begin{array}{l}\text { Hypothesized No. of } \\
\text { CE(s) }\end{array}$ & Eigenvalue & Trace Statistic & 0.05 Critical Value & Prob.** \\
\hline None ${ }^{*}$ & 0.380763 & 79.64473 & 69.81889 & 0.0067 \\
At most 1 & 0.275126 & 46.57532 & 47.85613 & 0.0656 \\
At most 2 & 0.173756 & 24.3741 & 29.79707 & 0.1851 \\
At most 3 & 0.129374 & 11.20441 & 15.49471 & 0.1993 \\
At most 4 & 0.023557 & 1.644918 & 3.841466 & 0.1997 \\
\hline
\end{tabular}

According to the Johamsen co-integration likelihood ratio test, the null hypothesis is rejected at the $5 \%$ significance level because of 79.64> 69.82, that is, the co-integration equation exists between the five variables and they has a long-term stable relationship.

\subsection{Granger Causality Test}

Through the co-integration test, we can draw a causal relationship between these five variables, but the specific relationship should be determined by Granger causality test of non-stationary sequences. The test results are shown in Table IV.

Table 4. The results of Granger causality test

\begin{tabular}{llll}
\hline Null Hypothesis: & Obs & F-Statistic & Prob. \\
\hline SP does not Granger Cause M1 & 70 & 1.68819 & 0.1929 \\
M1 does not Granger Cause SP & & 1.5481 & 0.2204 \\
SP does not Granger Cause M2 & 70 & 0.42776 & 0.6538 \\
M2 does not Granger Cause SP & & 1.45413 & 0.2411 \\
SP does not Granger Cause R1 & 70 & 0.20334 & 0.8165 \\
R1 does not Granger Cause SP & & 0.73893 & 0.4816 \\
SP does not Granger Cause R2 & 70 & 1.86634 & 0.1629 \\
R2 does not Granger Cause SP & & 0.11607 & 0.8906 \\
\hline
\end{tabular}

The test results shows that M1 and M2 were the cause of SP at the significance level of $22.04 \%$ and $24.11 \%$ respectively, while SP was Granger reason of M1 at the significance level of $19.29 \%$. That is to say, M1 and SP exist two-way causal relationship while M2 and SP exist one-way causal relationship from M2 to SP. R1 is the cause of SP at a significance level of $48.16 \%$, but SP is not the Granger cause of R1. That is, there is only one-way reason from R1 to SP between R1 and SP. SP is the Granger cause of R2 at a significance level of $16.29 \%$, but R2 is not significant to the Shanghai Composite Index, that is, there is only one-way reason from SP to R2. To sum up, the changes of M1, M2, R1 affect SP, but the change of R2 has no significant effect on SP. The change of SP will affect M1 and R2, but will not be significant of M2 and R1.

\subsection{Establish a VAR Model}

VAR model can be used to test the influence and the direction of influence of different variables. We can get the following test results at an optimal lag of 2 determined according to the AIC and SC guidelines. The test results are shown in Table V.

Table 5. The results of VAR model

\begin{tabular}{llllll}
\hline & M1 & M2 & R1 & R2 & SP \\
\hline M1(-1) & 0.592295 & -0.042355 & 0.961241 & 8.14033 & -0.969544 \\
M1(-2) & 0.308373 & 0.04438 & 1.423375 & 1.916521 & 0.583257 \\
M2(-1) & 0.003735 & 0.716715 & -0.87923 & -2.659399 & -0.720153 \\
M2(-2) & 0.036654 & 0.272843 & -0.857883 & -1.817654 & 0.931236 \\
R1(-1) & -0.035499 & -0.013515 & 0.579583 & 1.555445 & 0.00181 \\
R1(-2) & 0.024953 & 0.016811 & 0.313859 & -0.795359 & -0.030433 \\
R2(-1) & -0.000713 & -0.002546 & 0.020409 & 0.561734 & 0.000744 \\
\hline
\end{tabular}




\begin{tabular}{llllll}
\hline R2(-2) & 0.001849 & 0.00212 & 0.041317 & -0.242997 & 0.004035 \\
$\mathrm{SP}(-1)$ & 0.012668 & 0.006945 & 0.037403 & -1.340595 & 1.27392 \\
$\mathrm{SP}(-2)$ & -0.013775 & 0.00054 & -0.276422 & 1.385494 & -0.352701 \\
$\mathrm{C}$ & 0.77172 & 0.055897 & -3.839291 & -67.45858 & 2.750035 \\
R-squared & 0.991491 & 0.999214 & 0.979421 & 0.677522 & 0.92723 \\
Adj. R-squared & 0.990049 & 0.99908 & 0.975933 & 0.622865 & 0.914896 \\
Sum sq. residual & 0.00976 & 0.002877 & 0.421643 & 17.2756 & 0.180079 \\
F-statistics & 687.5212 & 7497.735 & 280.7964 & 12.39585 & 75.17766 \\
\hline
\end{tabular}

The test results show that in addition to the fifth column of data, the adjusted $\mathrm{R}^{\wedge} 2$ of other equations are greater than $90 \%$. So we can get the conclusion that the fitting result is pretty good.

In the first equation, doubling the previous period of SP will cause the money supply of M1 to increase by $1.27 \%$, doubling the previous two periods of SP, causing the M1 to decrease by $1.38 \%$. In the fifth equation, the previous period of M1 doubled, causing SP to decrease by $96.95 \%$, the first two periods of M1 doubled, causing $\mathrm{SP}$ to rise $58.32 \%$. This also shows that there is a two-way causal relationship between M1 and SP, consistent with the Granger test.

In the second equation, doubling the previous period of SP will result in an increase of $0.69 \%$ in the M2. The doubling of the first two periods of SP will cause a rise of $0.05 \%$ in M2, that is, the change in SP will hardly affect M2. In the fifth equation, doubling M2 in the previous period will cause the SP to fall by $72.02 \%$. In the first two periods, the doubling of M2 will result in an increase of SP by $93.12 \%$. That is, the change of M2 will significantly affect the SP. There is one-way causality from M2 to SP, which is consistent with the Granger test.

In the third equation, doubling the previous period of SP will cause R1 to rise by $3.74 \%$, doubling the previous two period of SP will cause R1 to decrease by $27.64 \%$. In the fifth equation, doubling R1 in the previous period will increase the SP by $0.18 \%$ and doubling the R1 in the first two periods will cause the SP to decrease by $3.04 \%$. That is to say, the change of R1 does not have a significant impact on SP, and there is a one-way causal relationship from SP to R1, which is inconsistent with Granger test results.

In the fourth equation, doubling the previous period of SP will cause R2 to fall by 1.34 . Doubling the first two period of SP will cause R2 to rise by 1.39 . That is, the change of SP will significantly affect the level of R2. In the fifth equation, a doubling of R2 in the previous period will cause an increase of $0.74 \%$ in SP, and a doubling of R2 in the first two periods will cause SP to rise by $0.40 \%$. That is, the change in R2 hardly affect the SP. So there is a one-way causal relationship from SP to R2, which is consistent with the result of Granger causality test.

\section{Conclusions}

Firstly, the change in M1 has a significant impact on the Shanghai Composite Index. The increase in the previous period will cause the Shanghai Composite Index to fall. The first two period increases will make the Shanghai Composite Index rise. However, the Shanghai Composite Index has a smaller impact on M1. In theory, an increase in the money supply will cause the stock market to rise. However, empirical results show that the increase of M1 in the first two periods leads to a marked rise in the Shanghai Composite Index, which can be interpreted as the lag effect of the monetary policy transmission. That is, Chinese stock market is not yet mature and the channel for monetary policy is not yet mature. Shanghai Composite Index has an impact on M1, but smaller, which can be interpreted as the result of the positive effects of wealth effect, portfolio effect and transaction effect being offset by the negative effect of alternative effect.

Secondly, changes of M2 will significantly affect the Shanghai Composite Index, and the previous period increase will cause the Shanghai Composite Index to fall, the first two period increase will cause the Shanghai Composite Index to rise. Shanghai Composite Index has no effect on M2. The impact of M2 on the Shanghai Composite Index is the same as that of M1, which also verifies the existence of lag effect of the monetary policy transmission.

Thirdly, Changes in the benchmark interest rate of one-year loans of financial institutions do not affect the Shanghai Composite Index. Changes in the Shanghai Composite Index will affect the one-year benchmark lending rates, the previous period of the Shanghai Composite Index will lead one-year benchmark lending rates to rise, the first two period increase will cause a decline. In theory, declines in one-year lending rates of financial institutions will result in an increase in corporate investment, resulting in an increase in corporate profits and the 
value of corporate shares, which will result in a rise in the stock price and an increase in the Shanghai Composite Index. However, the empirical result is that the level of one-year lending rates do not affect the Shanghai Composite Index. This also shows that China's monetary policy does not have a proper channel of transmission to the stock market and there is little connection between Chinese capital market and the monetary market. Since the benchmark lending rate of China is the official interest rate before interest rate liberalization finished and the change of Shanghai Composite Index arouses the adjustment of the benchmark interest rate, which means to a certain extent that the Chinese monetary authorities are concerned about and act on the stock market.

Fourthly, the changes in interbank interest rates do not affect the Shanghai Composite Index. Changes in the Shanghai Composite Index will significantly affect interbank lending rates. The rise of the former period of Shanghai Composite Index will cause the interbank lending rate to fall. The rise of the first two periods of the Shanghai Composite Index will cause the interbank lending rate to rise. The one-way causal relationship from Shanghai Composite Index to the interbank offered rates shows that there is a linkage between the Chinese capital market and the monetary market. According to Tobin's q theory, rising share prices will result in increased corporate investment, which in turn will result in higher interest rates. The effect of the previous two period change in the Shanghai Composite Index are same with the theory, which also proved the existence of the lag effect of transmission channels from the stock market to monetary market.

\section{Suggestions}

From the above analysis, it can be seen that the adjustment of the money supply (both in M1 and M2 levels) will have a significant impact on the stock market, but the fluctuation in the stock market has less impact on the money supply. Interest rate adjustments, whether the one-year benchmark lending rates of financial institutions or the inter-bank lending rate adjustments have no effect on the stock market, but the stock market ups and downs have an impact on the interest rate. Based on this, this article makes the following policy recommendations:

Firstly, China's transmission channel between the monetary market and the stock market exists but is not yet complete and has a long time lag. The monetary authorities should not include the adjustment of the stock market within the scope of monetary policy adjustment.

Secondly, as the drastic changes in the capital market will have a great impact on the real economy and affect the normal operation of the national economy. When the monetary authorities must take measures to intervene the capital market, it is suggested that the monetary supply policy is more effective.

\section{References}

Cao, Y. M., \& Xue, Y. G. (2008). Dynamic Correlation between Monetary Policy Variables and Stock Prices. Journal of Shanxi Finance University, 101-106. https://doi.org/10.3969/j.issn.1007-9556.2008.03.018

Fan, Y. Q., \& Wang, W. J. (2011). An Empirical Study on the Necessity of Monetary Policy Concerned with Stock Market. Journal of Yunnan Finance University, 27(4), 96-103.

Fu, S. H., \& Li, R. Y. (2013). Research on the Relationship between Stock Market Liquidity and Monetary Policy. Economic Research Guide, (31), 137-141. https://doi.org/10.3969/j.issn.1673-291X.2013.31.065

Guo, J. L., \& Li, W. J. (2004). An Empirical Analysis of the Interactive Relationship between the Development of Stock Market and Monetary Policy in China. Quantitative, Technical and Economic Research, 21(6), 18-27. https://doi.org/10.3969/j.issn.1000-3894.2004.06.003

Li, J., Tao, C., \& Zhao, S. (2015). An Empirical Study on the Impact of Monetary Policy on the Fluctuation of the Stock Market in China. Modern Business, (21), 165-167. https://doi.org/10.3969/j.issn.1673-5889.2015.21.092.

Liu, L., \& Meng, X. J. (2013). Research on the Relationship between Money Supply at All Levels and Stock Price in China. China Business, (23), 73-74. https://doi.org/10.3969/j.issn.1005-5800.2013.23.031

Long, G. S., \& Yang, X. S. (2006). Whether Monetary Policy Affects the Stock Market: An Empirical Study Based on Chinese Stock Market. Journal of Central University of Finance and Economics, (3), 39-44.

Su, G. (2015). Asymmetric Effects of Monetary Policy on Stock Market Liquidity Based on C - GARCH Model. China Management Informationization, 146-147. https://doi.org/10.3969/j.issn.1673-0194.2015.18.108

Wang, P. K. (2010). Can Monetary Policy Intervene in Asset Price Fluctuations - Based on the Study of Chinese 
Stock Market. Journal of Shanghai Administration Institute, 11(3), 97-107. https://doi.org/10.3969/j.issn.1009-3176.2010.03.012

Wang, T. J. (2015). Research on the Impact of China's Stock Market on Consumption. Economic and Trade Practice, (6), 43.

Wang, Y. (2010). An Empirical Analysis of the Impact of Monetary Policy Impacts on the Stock Market. New Finance (Theoretical version), (4). https://doi.org/10.3969/j.issn.1009-4202-B.2012.04.045

Wu, R. Y. (2010). Impact of Adjustments of Monetary Policy on Stock Market. New Finance, (7), 29-32.

Zhang, X. L. (2010). An Empirical Study on the Correlation between Money Supply and Stock Price in China. Economic Issues, (10), 89-92.

\section{Copyrights}

Copyright for this article is retained by the author(s), with first publication rights granted to the journal.

This is an open-access article distributed under the terms and conditions of the Creative Commons Attribution license (http://creativecommons.org/licenses/by/4.0/). 